\title{
Recombinant TsP53 modulates intestinal epithelial barrier integrity via upregulation of ZO-1 in LPS-induced septic mice
}

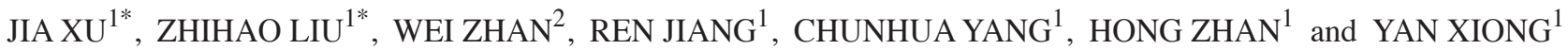 \\ ${ }^{1}$ Department of Emergency Medicine, The First Affiliated Hospital of Sun Yat-sen University, Guangzhou, \\ Guangdong 510080; ${ }^{2}$ Department of Emergency Medicine, The Third Affiliated Hospital of \\ Sun Yat-sen University, Guangzhou, Guangdong 510360, P.R. China
}

Received March 29, 2017; Accepted October 18, 2017

DOI: $10.3892 / \mathrm{mmr} .2017 .7946$

\begin{abstract}
Tight junctions (TJs) are a critical component in maintaining the intestinal mucosal barrier function and gastrointestinal health of animals. Gut barrier dysfunction contributes to the initiation and development of sepsis which induces an uncontrollable systemic inflammatory response and gives rise to life-threatening clinical conditions. Excretory-secretary antigens from Trichimella spiralis ( $T$. spiralis) have been reported to protect from sepsis in a mouse model, however the mechanism remains to be elucidated. Mice were treated with recombinant $T$. spiralis $53-\mathrm{kDa}$ glycoprotein (rTsP53) at 2 or $6 \mathrm{~h}$ following lipopolysaccharide (LPS) injection. Survival rate, serum systemic inflammation, Chiu's score, D-lactic acid (D-LA) and diamine oxidase (DAO) as intestinal injured biomarkers, bacterial translocation and growth in peritoneal fluid (PF) and mesenteric lymph nodes (MLN), intestinal tight junction structure and protein zona occludens (ZO)-1 expression were investigated. In LPS-induced septic mice, rTsP53 was demonstrated to protract the survival and inhibit serum systemic inflammatory response, and then, allayed morphological alteration, decreased the release of D-LA and DAO from intestines. Furthermore, LPS-induced intestinal permeability, bacterial translocation and growth in PF, MLN and vital organs were significantly suppressed by rTsP53 treatment. Notably, rTsP53 treatment markedly improved the intestinal tight junction damaged in sepsis via promoting ZO-1 expression. These results demonstrated that rTsP53
\end{abstract}

Correspondence to: Dr Yan Xiong or Dr Hong Zhan, Department of Emergency Medicine, The First Affiliated Hospital of Sun Yat-sen University, 58 Zhongshan 2nd Road, Guangzhou, Guangdong 510080, P.R. China

E-mail: xiongyan@mail.sysu.edu.cn

E-mail: zhanghong81@126.com

*Contributed equally

Key words: Trichimella spiralis antigens, intestinal epithelial barrier, intestinal tight junction, $\mathrm{ZO}-1$ protein ameliorated LPS-induced intestinal injury and is a potential protective agent for treatment of sepsis.

\section{Introduction}

Sepsis is a critical and life-threatening clinical condition, and is characteristic of a comprehensive systemic inflammatory response to infection. As sepsis progresses, severe pathophysiological conditions, such as multiple organ failure, shock, and death, commonly occur (1). Sepsis is positively associated with advanced age, in terms of both incidence and mortality (2). Several factors have been shown to contribute to the initiation and development of sepsis, including systemic inflammation, intestinal permeation, and a gut barrier with no integrity (3-7). Lipopolysaccharide (LPS) is commonly used for sepsis-induced systemic inflammation. It stimulates the immune system to release a series of cytokines and chemokines secreted by immune cells. In addition, LPS also causes gastrointestinal mucosal injury, involving prolongation of the transit time of intestinal epithelial cells and derangements in the intestinal barrier (3-5). Moreover, proinflammatory cytokines, oxidants, and reactive oxygen species (ROS) have been implicated as mediators of gut barrier dysfunction, such as intestinal permeation or barrier incompleteness $(6,7)$. However, the underlying mechanism of the impact of sepsis on the gastrointestinal tract remains elusive.

Sepsis is closely associated with damage to the intestinal epithelial barrier $(8,9)$. First, bacteria, pathogen-associated molecular patterns (PAMPs), and alarmins, and other intestinal lumen components leak into the bloodstream and, when subsequently combined with systemic inflammatory response syndrome, can bring about lethal multi-organ failure (10). Tight junctions play a critical role in the formation and maintenance of the intestinal epithelial barrier by strongly sealing adjacent intestinal mucosal cells at the apical site (11). Tight junction transmembrane proteins, such as occludins and claudins, potentiate adhesion by linking to cytoskeletal plaque proteins, for example, zona occludens (ZO)-1, -2, and -3 (12). However, the mutual regulation between sepsis and intestinal tight junctions is not completely understood.

Trichimella spiralis (T. spiralis) is a widely distributed parasitic nematode. A 53-kDa glycoprotein (TsP53) is a major component of the excretory-secretary antigens from 
T. spiralis and is expressed in much greater amounts in larvae (13). Interestingly, $T$. spiralis secretory products can alleviate immunological reactions in hosts with inflammatory and autoimmune diseases (14-18), such as sepsis, autoimmune encephalomyelitis, type I diabetes mellitus, and inflammatory bowel disease. The excretory-secretary antigens from T. spiralis can prolong survival and mitigate organ injury by decreasing sepsis-inducing inflammatory cytokines (14). Dendritic cells stimulated by excretory-secretary antigens showed significantly elevated production of interleukin (IL)-4, IL-10, and transforming growth factor- $\beta$ (TGF- $\beta$ ) at the systemic level, and in target organs, in a model of autoimmune encephalomyelitis, which was greatly reduced in severity by the excretory-secretary antigens (15). Moreover, infection with T. spiralis could inhibit the initiation and development of autoimmune diabetes in non-obese diabetic (NOD) mice, which spontaneously develop autoimmune diabetes via disruption of the T-helper-mediated destruction of insulin-producing $\beta$ cells (16). In addition, TsP53 can downregulate serum and colonic tumor necrosis factor- $\alpha$ (TNF- $\alpha$ ) while upregulating serum T-helper 2 anti-inflammatory cytokines (IL-4, IL-13) in experimental colitis, which in turn significantly improved the colitis activity index, as well as the macroscopic and microscopic scores $(17,18)$. The relationship between $T$. spiralis and intestinal tight junctions in sepsis is unknown.

In this study, we investigated whether recombinant TsP53 (rTsP53), a recently found protein, has effects on epithelial barrier disruption during sepsis in mice. Our results suggest that rTsP53 is a potential therapeutic protein for sepsis-stimulated systemic inflammation and intestinal epithelial barrier destruction.

\section{Materials and methods}

Animals, intravenous administration of rTsP53, and experimental design. Male BALB/c mice (weighing between 20 and $25 \mathrm{~g}$ ) were obtained from the Experimental Animal Center of Sun Yat-sen University and randomly divided into four groups: phosphate-buffered saline (PBS) group $(n=30)$, LPS group $(n=30)$, LPS $2 h+r T s P 53$ group $(n=30)$, and LPS $6 \mathrm{~h}+\mathrm{rTsP} 53$ group $(\mathrm{n}=30)$. Three independent experiments were performed. The experimental protocol was reviewed and approved by the Institutional Animal Care and Use Committee of Sun Yat-set University (Guangzhou, China), which was consistent with the UK Animals Act, 1986 and EU Directive 2010/63/EU for animal experiments. The sepsis model was induced by tail intravenous injection of LPS (10 mg/kg; Sigma-Aldrich; Merck KGaA, Darmstadt, Germany) via the caudal vein.

The rTsP53 was cloned, expressed, purified, and identified by us as previously described (17). For the in vivo study, the experimental groups consisted of the PBS group (normal mice treated with PBS, which was the solvent used for LPS and rTsP53); the LPS group (mice that received LPS $(10 \mathrm{mg} / \mathrm{kg}$ ) injection by tail intravenous injection); the LPS $2 \mathrm{~h}+\mathrm{rTsP} 53$ group [mice that received $50 \mu \mathrm{g}$ rTsP53 by tail intravenous injection $2 \mathrm{~h}$ after LPS (10 $\mathrm{mg} / \mathrm{kg}$ ) injection]; and the LPS $6 \mathrm{~h}+\mathrm{rTsP} 53$ group [mice that received $50 \mu \mathrm{g}$ rTsP53 by tail intravenous injection $6 \mathrm{~h}$ after LPS $(10 \mathrm{mg} / \mathrm{kg})$ injection]. Serum, lungs, intestines, and mesentery lymph node in the four groups were collected at $24 \mathrm{~h}$ after injection of PBS or LPS for further investigation.

Animal survival study. Animal survival was determined over a 72-hour time period. Animals were monitored every $12 \mathrm{~h}$ until the end of the 72-h study period. Mice were humanely killed upon the development of set end-point criteria (pertaining to mental state, eating and drinking, abdominal distention, respiratory distress and lethargy). All remaining animals were humanely killed at the end of the experiment.

Histopathology of the small intestine. The ileum $5 \mathrm{~cm}$ from the cecum was removed and opened longitudinally, and the damage was assessed histologically using a modified Chiu's score. The histological damage score was calculated on a 9-point scale (19). This scoring was done in a blinded fashion.

Transmission electron microscopy (TEM). For TEM, two $0.5 \times 0.5 \mathrm{~cm}$ mini-segments of intestinal tissue from each group were excised and placed in iced PBS buffer, fixed in $2 \%$ formaldehyde and $2 \%$ glutaraldehyde in PBS overnight, washed with PBS three times for 10 min each time, post fixed in $1 \%$ osmium tetroxide in PBS, dehydrated in a graduated series of ethanol solutions, and embedded in Spurr's epoxy resin. Samples were cut into $60-80 \mathrm{~nm}$ sections, and stained by saturated uranium acetate and lead citrate. The sections were analyzed by electronic microscopy (H-600 TEM; Hitachi Inc., Tokyo, Japan).

Preparation of GFP-positive E. coli. The PEGFP-N1 eukaryotic plasmid contains a gene coding for enhanced green fluorescent protein (EGFP). The prokaryotic plasmid PET-28b(+) contains a kanamycin resistance gene. We constructed a prokaryotic plasmid expressing both EGFP and kanamycin resistance using restriction endonucleases and ligase. This new double expression plasmid was named PET28b/EGFP and transfected into competent E. coli. EGFP and kanamycin resistance expressions in $E$. coli were detected using a fluorescence microscope and culturing in Luria-Bertani medium containing $100 \mu \mathrm{g} / \mathrm{ml}$ kanamycin. The extracted plasmid was digested by the restriction endonucleases NotI and HandIII. Agarose gel electrophoresis and ultraviolet light observation were used to identify the plasmid.

Evaluation of intestinal permeability. All animals were gavaged with kanamycin-resistant E. coli $\left[2 \times 10^{7} \mathrm{col}-\right.$ ony-forming units (CFU) suspended in $200 \mathrm{ml}$ of sterile saline]. Before the procedure, all mice were given sterile water containing $200 \mathrm{mg} / \mathrm{l} \mathrm{kanamycin}$ for 3 days, to restrain inherent intestinal flora, and gavaged with $1.5 \%$ sodium bicarbonate to neutralize stomach acid $30 \mathrm{~min}$ before $E$. coli intragastric administration. At $72 \mathrm{~h}$ after establishment of the sepsis model, peritoneal lavage fluids, mesenteric lymph nodes (MLN), liver, spleen, kidney, and intestine from animals in each group were collected and weighed, then ground with $500 \mu \mathrm{l}$ of sterile saline. The tissues were cultured at $37^{\circ} \mathrm{C}$ on lysogeny broth (LB) agar plates containing $100 \mathrm{mg} / \mathrm{ml}$ kanamycin to measure bacterial translocation. The plates were incubated for $24 \mathrm{~h}$ at $37^{\circ} \mathrm{C}$ and the bacterial CFU were 
counted. Results were expressed as $\mathrm{CFU} / \mathrm{ml} \pm \mathrm{SD}$. Bacterial colonies were collected and amplified in LB culture medium containing $100 \mathrm{mg} / \mathrm{ml}$ kanamycin. GFP-positive E. coli were identified by fluorescence microscopy.

Enzyme-linked immunosorbent assay (ELISA). Serum from animals from each group was collected at $0,6,12,24,48$, and $72 \mathrm{~h}$ after LPS injection. Blood was drawn from the caudal vein and the serum was stored at $-80^{\circ} \mathrm{C}$ until use. Serum levels of the cytokines IL- 6 and IL-10, and the chemokines D-lactic acid (D-LA) and diamine oxidase (DAO), were measured by ELISA using mouse-specific kits (R\&D Systems, Inc., Minneapolis, MN, USA).

Reverse transcription-quantitative polymerase chain reaction (RT-qPCR) and western blot analysis. At 6, 12, and $24 \mathrm{~h}$ after LPS injection, a part of the ileum $10 \mathrm{~cm}$ from the cecum was obtained, weighed, and used to measure intestinal RNA and protein content. Total cellular RNA was extracted using TRIzol (Invitrogen, Carlsbad, CA, USA) and transcribed to cDNA using the SuperScript III reverse transcriptase kit according to the manufacturer's instructions (Invitrogen). Quantitative real-time PCR was performed on an Applied Biosystems 7500 real-time PCR detection system to determine gene expression for ZO-1 using validated TaqMan gene expression assay primer/probe combinations (Applied Biosystems; Thermo Fisher Scientific, Inc., Waltham, MA, USA). All samples were run in triplicate and relative mRNA expression levels were determined after normalizing all values to $18 \mathrm{~S} \mathrm{RNA} . \Delta \mathrm{Ct}$ was calculated as the difference between the cycle threshold $(\mathrm{Ct})$ for the gene of interest and the respective $\mathrm{Ct}$ for $18 \mathrm{~S}$. Primer sequences for ZO-1 were: Forward, 5'-GATGACCGACTC TTTCTC-3' and reverse, 5'-CAATCTCCAGTTCCTCTT-3'. Primer sequences for $\beta$-actin were: Forward, 5'-GAAATC GTGCGTGACATCAAAG-3' and reverse, 5'-TGTAGTTTC ATGGATGCCACAG-3'.

Ileal protein extracts were analyzed by western blotting with anti-ZO-1 $(1: 1,000)$ or anti- $\beta$-actin $(1: 5,000)$ antibodies (Sigma-Aldrich; Merck KGaA) overnight at $4^{\circ} \mathrm{C}$. After washing, the membrane was incubated with horseradish peroxidase (HRP)-conjugated secondary antibodies (Cell Signaling Technology, Danvers, MA, USA). $\beta$-actin was used as an internal control. Densitometry was performed using ImageJ software (NIH, Bethesda, MD, USA). The optical density (OD) of the target protein was normalized to that of $\beta$-actin and presented as a percentage of the control.

Statistical analysis. Data are presented as means \pm SD. Statistical significance was determined by Student's t-test analysis or one-way ANOVA. Survival data were analyzed by the log-rank test using SPSS software (version 17.0; SPSS Inc., Chicago, IL, USA). A P-value of $<0.05$ was accepted as statistically significant.

\section{Results}

rTsP53 intervention protected mice from LPS-induced systemic inflammation and lethality (Table I and Fig. 1) rTsP53 treatment improved survival and organ function after LPS-induced sepsis. To investigate whether rTsP53 has a protective effect against sepsis, we compared the rate of mortality induced by LPS in endotoxemic mice, a model of human sepsis, with or without rTsP53 treatment. The mortality rate of mice in four different groups was calculated (Table I). There were statistically significant improvements in the survival of mice in the LPS $2 \mathrm{~h}+\mathrm{rTsP} 53$ and LPS $6 \mathrm{~h}+\mathrm{rTsP} 53$ groups at five different time-points, compared with the LPS group. Mice in the LPS $2 \mathrm{~h}+\mathrm{rTsP} 53$ group showed a significant decrease in mortality compared with the LPS $6 \mathrm{~h}+\mathrm{rTsP} 53$ group. The results suggest that rTsP53 can protect against LPS-induced death in mice and treatment with rTsP53 $2 \mathrm{~h}$ after injection of LPS was more effective.

We used the Acute Lung Injury Score to quantify the effects of rTsP53 on lung injury. The lungs of mice receiving LPS presented congested alveolar capillaries, hemorrhage, inflammatory cell infiltration, and a degree of alveolar wall thickening, which was greatly ameliorated in rTsP53-treated groups (Fig. 1A and B). Moreover, LPS remarkably elevated the concentration of liver enzymes [alanine aminotransferase (ALT) and aspartate aminotransferase (AST)], which were released from liver cells damaged by LPS, while rTsP53 treatment could alleviate the release of ALT and AST (Fig. 1C and D). Blood urea nitrogen (BUN) and serum creatinine (Scr), as biomarkers of kidney function, were markedly decreased in the rTsP53-treated groups compared with the LPS group (Fig. 1E and F). Interestingly, the Acute Lung Injury Score, and serum ALT, AST, BUN and Scr in the LPS $6 \mathrm{~h}+\mathrm{rTsP} 53$ group were much higher than in the LPS $2 \mathrm{~h}+\mathrm{rTsP} 53$ group. These results indicate that rTsP53 can protect mice from LPS-induced organ damage and treatment following LPS injection was more effective at 2 vs. $6 \mathrm{~h}$.

Effect of rTsP53 on plasma cytokine concentration. We hypothesized that the protection of rTsP53 in septic mice may be due to regulation of the immune response to infection. Next, we studied the proinflammatory cytokines IL-6 and TNF- $\alpha$, and the anti-inflammatory cytokine IL-10. In comparison to the PBS group, the inflammatory mediators IL- 6 and IL-10 reached their maximum at $12 \mathrm{~h}$, while and TNF- $\alpha$ reached its peak value at $1 \mathrm{~h}$ after LPS administration. However, when mice were treated with rTsP53, particularly $2 \mathrm{~h}$ after LPS injection, serum levels of the proinflammatory cytokines IL- 6 and TNF- $\alpha$ were lower compared with those of the LPS group (Fig. 1G and H). Similarly, the concentration of the anti-inflammatory cytokine IL-10 gradually increased in rTsP53-treated groups compared with the LPS group (Fig. 1I). These results suggest that rTsP53 could downregulate LPS-induced inflammatory factors and upregulate anti-inflammatory factors.

rTsP53 treatment lessened intestinal barrier injury in LPS-induced septic mice (Fig. 2)

Changes in histopathology and Chiu's score in the small intestine. In the PBS group, histopathology revealed normal villi with an integrated structure and neat arrangement (Fig. 2A). There was distinctive damage to the intestinal mucosa in the LPS group, with massive epithelial lifting, broken tops, exposed capillaries, inflammatory cell infiltration, ulceration, and hemorrhage in the lamina propria (Fig. 2A). Compared with the LPS group, the histopathological changes 
Table I. Mortality rate in four groups in the five time-points following LPS injection.

\begin{tabular}{|c|c|c|c|c|}
\hline Time & PBS $(\%)$ & LPS (\%) & LPS 2 h+rTsP53 (\%) & LPS 6 h+rTsP53 (\%) \\
\hline $12 \mathrm{~h}$ & $0 / 30(0)$ & $7 / 30(23.3)$ & $1 / 30(3.3)^{\mathrm{a}}$ & $3 / 30(10)^{\mathrm{a}}$ \\
\hline $24 \mathrm{~h}$ & $0 / 30(0)$ & $14 / 30(45.3)$ & $3 / 30(10)^{\mathrm{a}, \mathrm{b}}$ & $8 / 30(25.7)^{\mathrm{a}}$ \\
\hline $36 \mathrm{~h}$ & $0 / 30(0)$ & $15 / 30(48.7)$ & $4 / 30(13.3)^{\mathrm{a}, \mathrm{b}}$ & $9 / 30(28.7)^{\mathrm{a}}$ \\
\hline $48 \mathrm{~h}$ & $0 / 30(0)$ & $19 / 30(63.7)$ & $5 / 30(16.7)^{\mathrm{a}, \mathrm{b}}$ & $10 / 30(34)^{\mathrm{a}}$ \\
\hline $72 \mathrm{~h}$ & $0 / 30(0)$ & $21 / 30(70)$ & $6 / 30(20)^{a, b}$ & $11 / 30(38)^{\mathrm{a}}$ \\
\hline
\end{tabular}

Values are mean \pm standard deviation. ${ }^{a} \mathrm{P}<0.05$ vs. LPS group; ${ }^{b} \mathrm{P}<0.05$ vs. LPS $6 \mathrm{~h}+\mathrm{rTsP} 33$ group. Three independent experiments were performed.
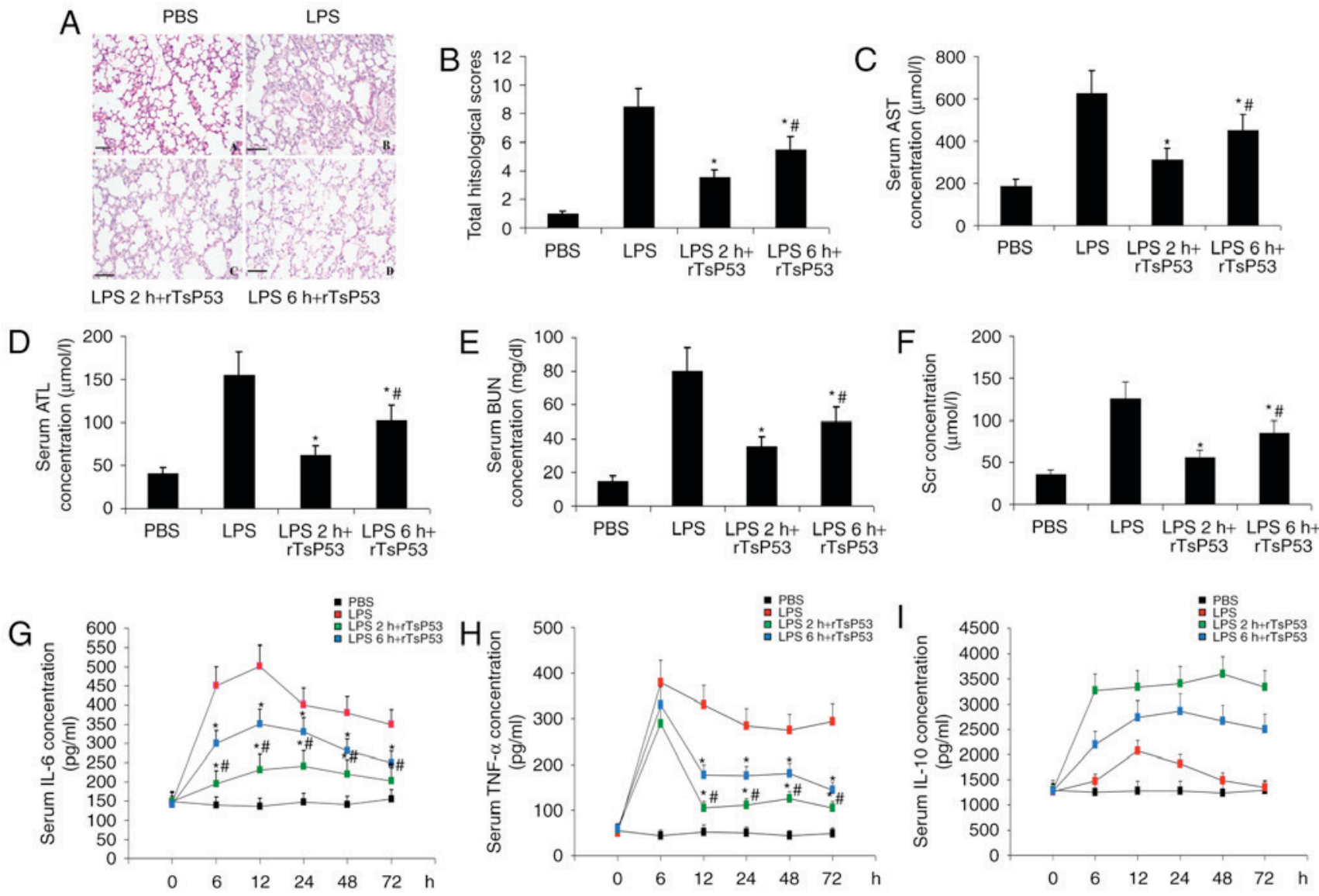

Figure 1. rTsP53 intervention protects mice from LPS-induced systemic inflammation and lethality. (A) Representative H\&E stained sections of lung were shown after $24 \mathrm{~h}$ following injection of LPS. Original magnification, x100. (B) The severity of pneumonia was evaluated by total histological scores. Values are means $\pm \mathrm{SD},{ }^{*} \mathrm{P}<0.005$ vs. LPS group; ${ }^{\mathrm{P}}<0.001$ vs. LPS $2 \mathrm{~h}+\mathrm{rTsP} 53$ group. (C and D) AST and ALT were determined after $24 \mathrm{~h}$ following injection of LPS. Values are means $\pm \mathrm{SD},{ }^{*} \mathrm{P}<0.005$ vs. LPS group; ${ }^{*} \mathrm{P}<0.01$ vs. LPS $2 \mathrm{~h}+\mathrm{rTsP} 53$ group. (E and F) BUN and Scr were accessed after $24 \mathrm{~h}$ following injection of LPS. Values are means $\pm \mathrm{SD},{ }^{*} \mathrm{P}<0.05$ vs. LPS group; ${ }^{*} \mathrm{P}<0.05$ vs. LPS $2 \mathrm{~h}+\mathrm{rTsP} 53$ group. (G-I) IL- 6 , TNF- $\alpha$, and IL-10 were determined in the six time-points following injection of LPS. Values are means $\pm \mathrm{SD},{ }^{*} \mathrm{P}<0.01$ vs. LPS group; ${ }^{*} \mathrm{P}<0.05$ vs. LPS 2 h+rTsP53 group. All statistical significance was determined by one-way ANOVA analysis.

in the lamina propria in rTsP53-treated groups were obviously improved, showing few broken tops, very slight inflammatory cell infiltration, smaller ulcers, and little hemorrhage in the lamina propria (Fig. 2A). The LPS 2 h+rTsP53 group had the lowest Chiu's score, while the LPS group had the highest. Interestingly, Chiu's score for the LPS $2 \mathrm{~h}+\mathrm{rTsP} 53$ group was significantly lower than that for the LPS $6 \mathrm{~h}+\mathrm{rTsP} 53$ group. These data show that rTsP53 treatment attenuated histopathological damage to the intestinal mucosa during sepsis.
Changes in the plasma concentrations of D-LA and DAO. Due to the intestinal benefit of rTsP53 in septic mice, we hypothesized that rTsP53 could regulate the serum levels of D-LA, a product of intestinal bacteria glycolysis, and DAO, a high-activity intracellular enzyme in the intestinal villi, both of which can be released into the blood from damaged intestinal mucosa. The serum level of D-LA reached a peak at $6 \mathrm{~h}$ following LPS injection and remained at a relatively high level until $72 \mathrm{~h}$ compared with the PBS group. However, rTsP53 
A

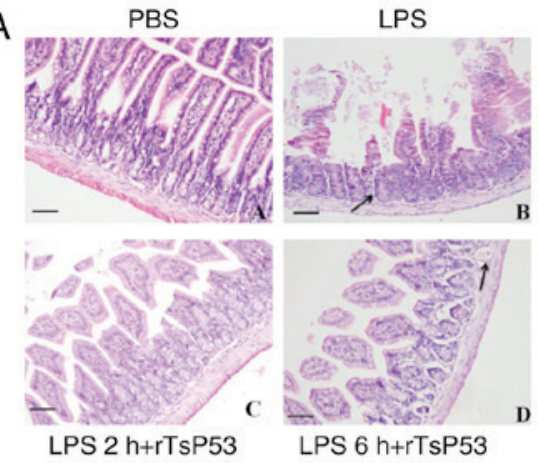

B

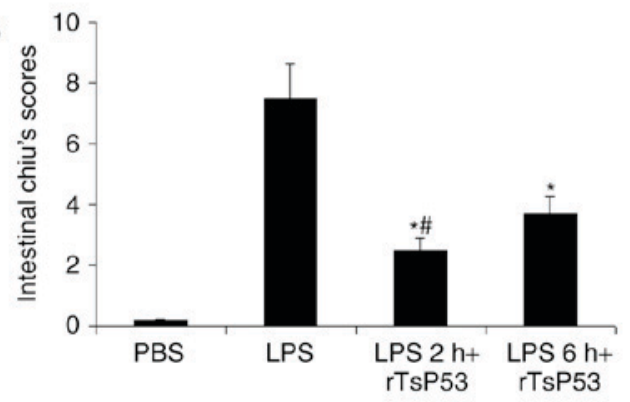

C
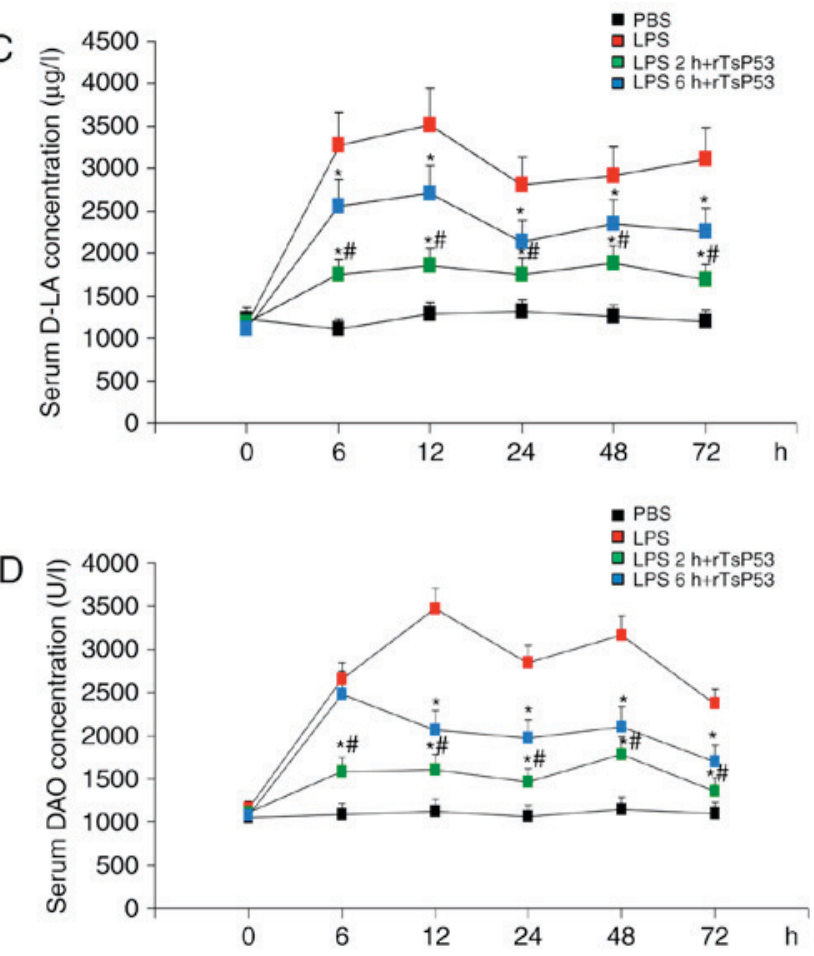

Figure 2. rTsP53 treatment improves intestinal barrier injury in LPS-induced septic mice. (A) H\&E staining of small intestine sections were shown after $24 \mathrm{~h}$ following injection of LPS. Original magnification, x200. (B) The severity of small intestine damaged by LPS was evaluated by total histological scores. Values are means $\pm \mathrm{SD},{ }^{*} \mathrm{P}<0.05$ vs. LPS group; ${ }^{*} \mathrm{P}<0.05$ vs. LPS $6 \mathrm{~h}+\mathrm{rTsP} 53$ group. The statistical significance was evaluated by one-way ANOVA analysis. (C and D) D-LA and DAO were determined in the six different time-points following injection of LPS. Values are means \pm SD, ${ }^{*} \mathrm{P}<0.05$ vs. LPS group; ${ }^{~} \mathrm{P}<0.05$ vs. LPS 2 h+rTsP53 group.

treatment reduced the concentration of D-LA in plasma, and the D-LA level in the LPS $2 \mathrm{~h}+\mathrm{rTsP} 53$ group was much lower than that in the LPS $6 \mathrm{~h}+\mathrm{rTsP} 53$ group (Fig. 2C). Similar results were observed in the alteration of DAO concentration during sepsis (Fig. 2D). These results show that rTsP53 can modulate sepsis-induced intestinal mucosal damage.

rTsP53 treatment facilitated LPS-induced intestinal permeability, bacterial translocation, and growth (Fig. 3)

rTsP53 treatment decreased bacterial translocation and growth in PF and MLN in septic mice. Mice subjected to LPS had significantly increased bacterial translocation and growth in PF and MLN compared with the PBS group. rTsP53 treatment significantly inhibited bacterial growth in PF and MLN in septic mice. Bacterial burden in PF and MLN in the LPS $2 \mathrm{~h}+\mathrm{rTsP} 53$ group was lower than in the LPS $6 \mathrm{~h}+\mathrm{rTsP} 53$ group (Fig. 3A and B).

rTsP53 treatment decreased bacterial translocation and growth in intra-abdominal organs. We also examined recombinant $E$. coli translocation and bacterial burden in other intra-abdominal organs, such as the liver, spleen, kidney, and intestine. Mice in the LPS group had higher levels of bacterial translocation and burden in each organ (liver, 5.5 \pm 0.89 $\log 10 \mathrm{CFU} / \mathrm{ml} / \mathrm{g}$ for the LPS group vs. $0.35 \pm 0.08 \log 10 \mathrm{CFU} /$ $\mathrm{ml} / \mathrm{g}$ for the PBS group; spleen, $4.9 \pm 0.78 \log 10 \mathrm{CFU} / \mathrm{ml} / \mathrm{g}$ for the LPS group vs. $0.4 \pm 0.09 \log 10 \mathrm{CFU} / \mathrm{ml} / \mathrm{g}$ for the PBS group; kidney, $4.5 \pm 0.72 \log 10 \mathrm{CFU} / \mathrm{ml} / \mathrm{g}$ for the LPS group vs. $0.25 \pm 0.05 \log 10 \mathrm{CFU} / \mathrm{ml} / \mathrm{g}$ for the PBS group; intestine, $9 \pm 1.44 \log 10 \mathrm{CFU} / \mathrm{ml} / \mathrm{g}$ for the LPS group vs. $2.89 \pm 0.59$ $\log 10 \mathrm{CFU} / \mathrm{ml} / \mathrm{g}$ for the PBS group, $\mathrm{P}<0.05)$. Mice in the LPS $2 \mathrm{~h}+\mathrm{rTsP} 53$ group showed a significant decrease in bacterial translocation and growth in these organs compared with the LPS group (liver, $1.3 \pm 0.22 \log 10 \mathrm{CFU} / \mathrm{ml} / \mathrm{g}$; spleen, $1.8 \pm 0.30$ $\log 10 \mathrm{CFU} / \mathrm{ml} / \mathrm{g}$; kidney, $1.3 \pm 0.22 \log 10 \mathrm{CFU} / \mathrm{ml} / \mathrm{g}$; intestine, $2.2 \pm 0.37 \log 10 \mathrm{CFU} / \mathrm{ml} / \mathrm{g}$ ), and the bacterial translocation and burden in the LPS $2 \mathrm{~h}+\mathrm{rTsP} 53$ group were greatly decreased compared with the LPS $6 \mathrm{~h}+\mathrm{rTsP} 53$ group (liver, $3.3 \pm 0.40$

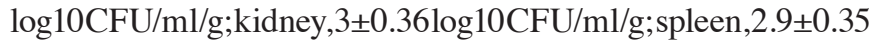
$\log 10 \mathrm{CFU} / \mathrm{ml} / \mathrm{g}$; intestine, $4.5 \pm 054 \log 10 \mathrm{CFU} / \mathrm{ml} / \mathrm{g}$ ) (Fig. 3C).

rTsP53 treatment alleviated tight junction destabilization (Fig. 4)

rTsP53 treatment reduced damage to the ultrastructure of the tight junction. In the PBS group, TEM revealed intact epithelial cells in the intestinal mucosa, complete integrity of the tight junction, orderly villi of the epithelial cells, and whole tight junctions (Fig. 4A). However, in the LPS group, the epithelial cells were distributed in a disorderly manner with noticeable exfoliation, shrinkage, and disordered villi, which are characteristic of epithelial cells undergoing necrocytosis. Furthermore, other morphological changes were observed in septic mice, such as swelling of mitochondria, lysosome activation, and neutrophil infiltration, which were significantly improved in the rTsP53-treated groups (Fig. 4A).

rTsP53 treatment regulated expression of $\mathrm{ZO}-1$ in intestinal tissues. ZO-1 is an important tight junction protein, which are critical structural proteins for maintaining mucosal barrier 
A
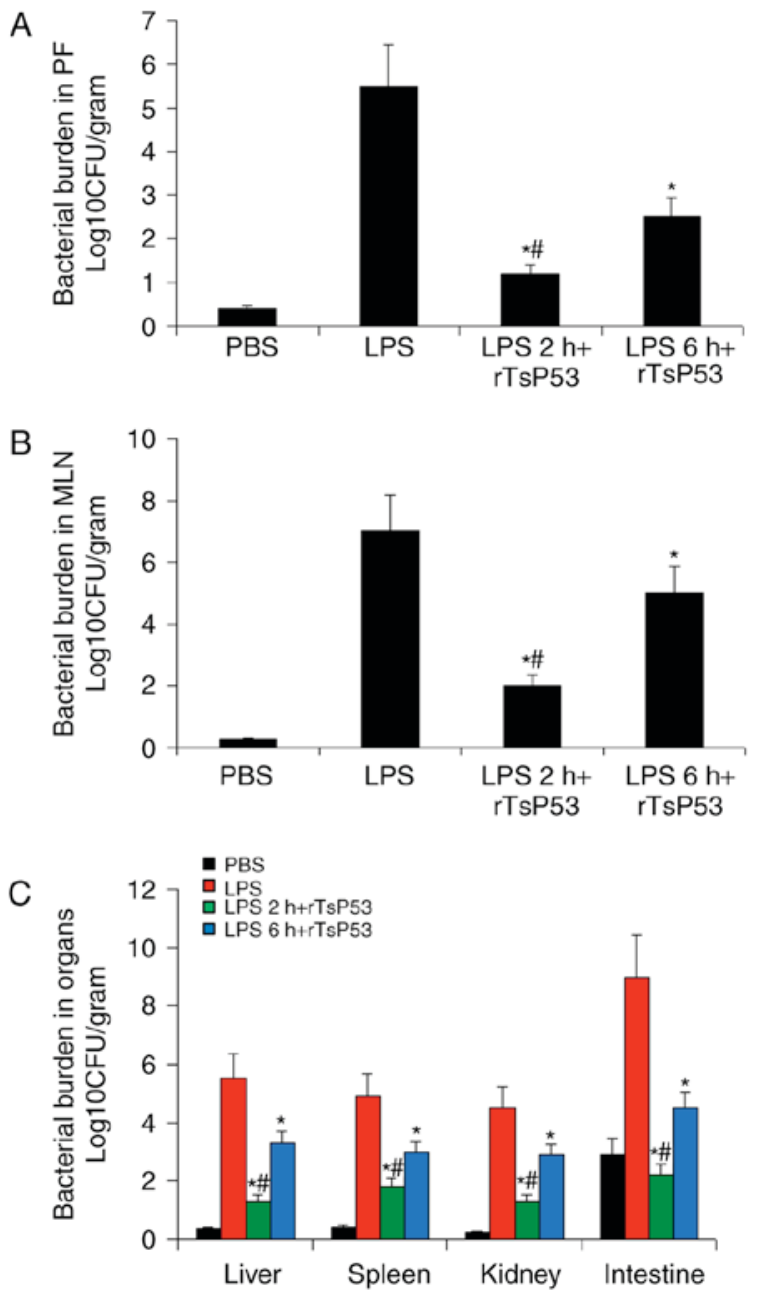

Figure 3.rTsP53 treatment protects mice from LPS-induced intestinal permeability, bacterial translocation and growth. (A-C) All animals were gavaged with $2 \times 10^{7} \mathrm{CFU}$ suspended in $200 \mathrm{ml}$ of sterile saline. Seventy-two hours after establishment of sepsis model, peritoneal lavage fluids (PF), MLN, liver spleen, kidney and intestine from animals of different groups were collected. The tissues were cultured at $37^{\circ} \mathrm{C}$ on agar plates containing $100 \mathrm{mg} / \mathrm{ml}$ of kanamycin to measure bacterial translocation. The plates were incubated for $24 \mathrm{~h}$ at $37^{\circ} \mathrm{C}$ and then counted for bacterial colony-forming units (CFUs). Values were expressed as $\mathrm{CFU} / \mathrm{ml} \pm \mathrm{SD}$. ${ }^{\text {}} \mathrm{P}<0.005$ vs. LPS group; ${ }^{\text {"P}} \mathrm{P}<0.05$ vs. LPS $2 \mathrm{~h}+\mathrm{rTsP} 53$ group. All statistical significance was assessed by one-way ANOVA analysis.

function. Impairment of mucosal barrier function is characterized by the aberrant expression of tight junction proteins. Immunoblotting analysis was used to detect the expression of the ZO-1 protein. As shown in Fig. 4B, the expression of $\mathrm{ZO}-1$ was significantly downregulated at $6 \mathrm{~h}$ and decreased further at $24 \mathrm{~h}$ after LPS administration in the small intestine. This indicates that LPS rapidly degrades ZO-1 protein and disrupts the structure of the tight junction. However, in the LPS $2 \mathrm{~h}+\mathrm{rTsP} 53$ group, the expression level of the ZO-1 protein was increased significantly, and continued to increase slowly over time, compared with that of the LPS group. In the LPS $6 \mathrm{~h}+\mathrm{rTsP} 53$ group, ZO-1 protein was more highly expressed than in the LPS group, but the levels were lower than in the LPS $2 \mathrm{~h}+\mathrm{rTsP} 53$ group. These results suggest that rTsP53 protein has a protective effect on the tight junction in small intestines injured by LPS, especially when rTsP53 was injected $2 \mathrm{~h}$ after LPS administration.
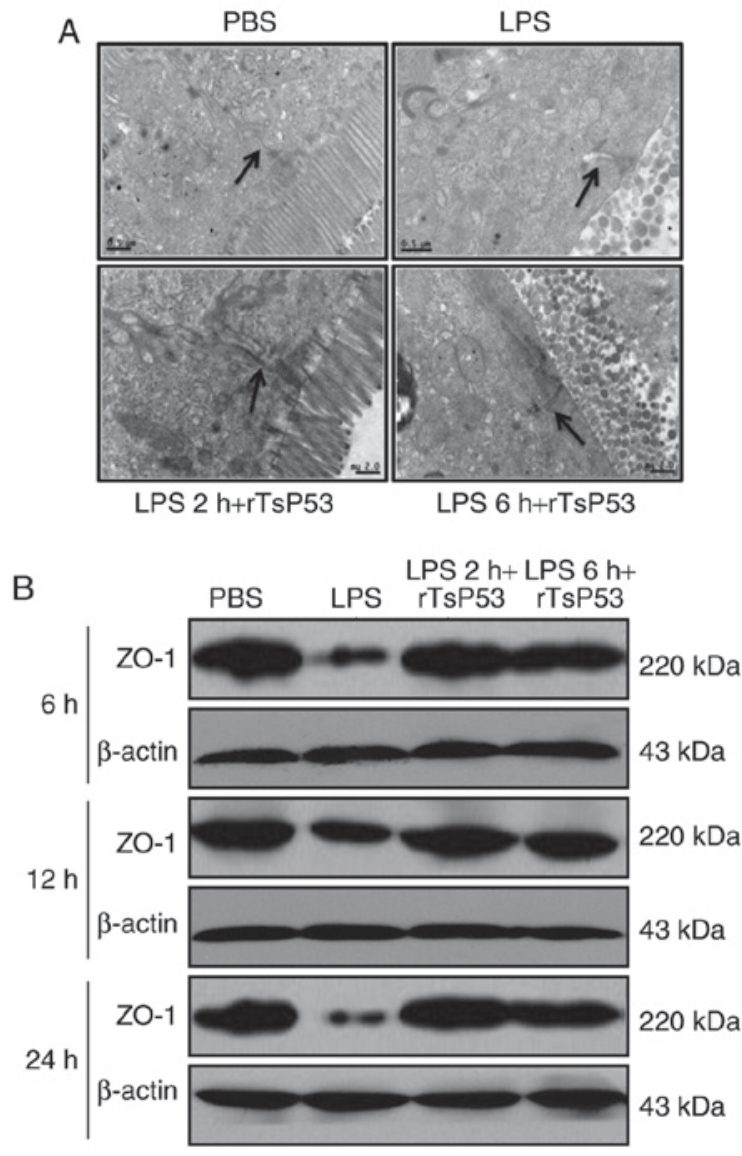

Figure 4. rTsP53 treatment contributes to alleviation of tight junction destabilization. (A) The ultrastructure of small intestines in four groups evaluated by transmission electron microscopy. Black arrow indicated the gap between villi and submucosa. (B) Western blotting of ZO-1 in small intestine mucosa from mice in three different time-points following injection of LPS. $\beta$-actin was used as the control for loading.

\section{Discussion}

Following sepsis-induced intestinal ischemia and hypoxia, ROS, cytokines, and inflammatory mediators underlie the molecular mechanisms of intestinal mucosal injury and barrier dysfunction (20). The improvement of intestinal mucosal permeability during sepsis, to avoid gut-derived secondary infection, is a crucial measure to prevent the initiation and development of sepsis. In the present study, we found that a newly discovered protein, rTsP53, could efficiently protect mice against LPS-induced sepsis. rTsP53 alleviated sepsis-induced multi-organ injuries in the lung, liver, and kidney, remarkably downregulated systematic inflammation, and mitigated intestinal permeability by decreasing ZO-1 expression, which can lead to bacterial translocation. Our results suggest that rTsP53 may be a potential mitigator in the treatment of sepsis.

The excretory-secretory antigens of $T$. spiralis were first found to have immunosuppression functions 20 years ago (21), but the mechanism remains unknown. TsP53, a $53-\mathrm{kDa}$ glycoprotein, is a major component protein of the excretory-secretory antigens of $T$. spiralis. It is thought that rTsP53 can stimulate strong IgG1 production with low IgG2a induction in immunized mice, and is considered a T-cell-prone immunomodulator (22). In this study, rTsP53 significantly 
downregulated TNF- $\alpha$ and IL-6 in septic mice and upregulated anti-inflammatory cytokine IL-10 levels. LPS-induced sepsis is a T-helper cell-driven inflammation process, in which TNF- $\alpha$, IL-6, and IL-10 have a fundamental effect on triggering leukocyte activation and tissue accumulation. This may explain why rTsP53 has a major influence in LPS-induced organ damage. Our research showed that rTsP53 treatment can number the amount of congested alveolar capillaries, reduce inflammatory cell infiltration, decrease alveolar wall thickening in the lungs, and reduce concentrations of ALT and AST (indicators of liver function) and BUN and Scr (surrogates of kidney function). Therefore, we reason that rTsP53 exerts a protective effect against sepsis-induced organ injury partly through the modulation of immunological function.

It is generally thought that the intestines play a 'motor' role in systemic inflammatory response syndrome. During sepsis, massive release of inflammatory factors, intestinal ischemia and hypoxia, and cytotoxicity, impair the tight junctions between epithelial cells and cause intestinal mucosal barrier dysfunction and intestinal bacterial translocation, which can induce an endogenous 'second hit' to the body (23). The intestinal mechanical barrier is composed of mucosal epithelium, intercellular tight junctions, lamina propria, adherent junctions, and intestinal secretions. Tight junctions play an important role in maintaining the integrity of the mucosal epithelium (24,25). In our study, ZO-1, a tight junction protein, was remarkably enhanced by rTsP53 treatment in the intestinal epithelium and rTsP53 improved epithelial integrity with lower amounts of shortened villi and withered crypts. rTsP53-mediated increased ZO-1 expression, and improved mucosal permeability, contributed to reduced bacterial translocation into the blood and organs and lessened the systemic inflammatory storm. Further studies are needed to explore the upstream mechanism of ZO-1-mediated tight junction dysfunction in sepsis-induced intestinal injury.

In conclusion, this study demonstrates that rTsP53 plays a protective role in LPS-induced sepsis and prevents sepsis-induced intestinal injury via modulation of ZO-1 expression. These results have implications for the potential therapeutic use of rTsP53 in patients with sepsis.

\section{Acknowledgements}

This study was supported by the Training Funds for young Scholars of Sun Yat-sen University (no. 11ykpy13) and Guangdong Province Science and Technology Foundation (nos. A2015486, 2016A030313249, 2016A030310159, and S2013010015328). The English in this study has been checked by at least two professional editors, both native speakers of English. For a certificate, please see (http://www.textcheck.com/certificate/rcy900).

\section{References}

1. Moreira J: Severe sepsis and septic shock. N Engl J Med 369: 2063, 2013

2. Starr ME and Saito H: Sepsis in old age: Review of human and animal studies. Aging Dis 5: 126-136, 2014.
3. Sappington PL, Han X, Yang R, Delude RL and Fink MP: Ethyl pyruvate ameliorates intestinal epithelial barrier dysfunction in endotoxemic mice and immunostimulated caco-2 enterocytic monolayers. J Pharmacol Exp Ther 304: 464-476, 2003.

4. Fink MP: Intestinal epithelial hyperpermeability: Update on the pathogenesis of gut mucosal barrier dysfunction in critical illness. Curr Opin Crit Care 9: 143-151, 2003.

5. DeMeo MT, Mutlu EA, Keshavarzian A and Tobin MC: Intestinal permeation and gastrointestinal disease. J Clin Gastroenterol 34: 385-396, 2002.

6. Touqui L and Alaoui-EI-Azher M: Mammalian secreted phospholipases A2 and their pathophysiological significance in inflammatory diseases. Curr Mol Med 1: 739-754, 2001.

7. Lilja I, Dimberg J, Sjödahl R, Tagesson C and Gustafson-Svärd C: Effects of endotoxin and dexamethasone on group I and II phospholipase A2 in rat ileum and stomach. Gut 35: 40-45, 1994.

8. John LJ, Fromm M and Schulzke JD: Epithelial barriers in intestinal inflammation. Antioxid Redox Signal 15: 1255-1270, 2011.

9. Turner JR: Intestinal mucosal barri17er function in health and disease. Nat Rev Immunol 9: 799-809, 2009.

10. Balzan S, de Almeida Quadros C, de Cleva R, Zilberstein B and Cecconello 1: Bacterial translocation: Overview of mechanisms and clinical impact. J Gastroenterol Hepatol 22: 464-471, 2007.

11. Farquhar MG and palade GE: Junctional complexes in various epithelia. J Cell Biol 17: 375-412, 1963.

12. Niessen CM: Tight junctions/adherens junctions: Basic structure and function. J Invest Dermatol 127: 2525-2532, 2007.

13. Nagano I, Wu Z and Takahashi Y: Species-specific antibody responses to the recombinant 53-kilodalton excretory and secretory proteins in mice infected with Trichinella spp. Clin Vaccine Immunol 15: 468-473, 2008.

14. Du L, Liu L, Yu Y, Shan H and Li L: Trichinella spiralis excretory-secretory products protect against polymicrobial sepsis by suppressing MyD88 via mannose receptor. Biomed Res Int 2014: 898646, 2014.

15. Sofronic-Milosavljevic LJ, Radovic I, IIic N, Majstorovic I, Cvetkovic J and Gruden-Movsesijan A: Application of dendritic cells stimulated with Trichinella spiralis excretory-secretory antigens alleviates experimental autoimmune encephalomyelitis. Med Microbiol Immunol 202: 239-249, 2013.

16. Saunders KA, Raine T, Cooke A and Lawrence CE: Inhibition of autoimmune type 1 diabetes by gastrointestinal helminth infection. Infect Immun 75: 397-407, 2007.

17. Du L, Tang H, Ma Z, Xu J, Gao W, Chen J, Gan W, Zhang Z, $\mathrm{Yu} X$, Zhou X and $\mathrm{Hu} X$ : The protective effect of the recombinant 53-kDa protein of Trichinella spiralis on experimental colitis in mice. Dig Dis Sci 56: 2810-2817, 2011.

18. Du L, Wei H, Li L, Shan H, Yu Y, Wang Y and Zhang G: Regulation of recombinant Trichinella spiralis 53-kDa protein (rTsP53) on alternatively activated macrophages via STAT6 but not IL-4R $\alpha$ in vitro. Cell Immunol 288: 1-7, 2014.

19. Chiu CJ, McArdle AH, Brown R, Scott HJ and Gurd FN: Intestinal mucosal lesion in low-flow states. I. A morphological, hemodynamic, and metabolic reappraisal. Arch Surg 101: 478-483, 1970.

20. Li Y, Li Q, Chen H, Wang T, Liu L, Wang G, Xie K and Yu Y: Hydrogen gas alleviates the intestinal injury caused by severe sepsis in mice by increasing the expression of Heme oxygenase-1. Shock 44: 90-98, 2015.

21. Stewart GL, Wood B and Boley RB: Modulation of host response by trichinella pseudospiralis. Parasite Immunol 7: 223-233, 1985.

22. Du L, Tang H, Ma Z, Xu J, Gao W, Chen J, Gan W, Zhang Z, Yu X, Zhou X and Hu X: The protective effect of the recombinant 53-kDa protein of Trichinella spiralis on experimental colitis in mice. Dig Dis Sci 56: 2810-2827, 2011.

23. Al-Sadi R, Guo S, Ye D, Rawat M and Ma TY: TNF- $\alpha$ modulation of intestinal tight junction permeability if mediated by NIK/IKK- $\alpha$ axis activation of the canonical NF- $\kappa B$ pathway. Am J Pathol 186: 1151-1165, 2016.

24. Yu YB and Li YQ: Enteric glial cells and their role in the intestinal epithelial barrier. World J Gastroenterol 20: 11273-11280, 2014.

25. Wardill HR and Bowen JM: Chemotherapy-induced mucosal barrier dysfunction: An updated review on the role of intestinal tight junctions. Curr Opin Support Palliat Care 7: 155-161, 2013. 